\title{
Morfogênese e consumo de água de estacas de romã sob aplicação de fitormônios exógenos
}

\author{
João Paulo da Silva ${ }^{l}$; Rener Luciano de Souza Ferraz $*^{*}$; Alexandre Eugenio da Silva ${ }^{l}$; Patricia da Silva Costa ${ }^{2}$; \\ Antonio Manoel da Silva ${ }^{3}$; Kaline de Souza Meiral. \\ ${ }^{1}$ Universidade Estadual da Paraíba, jpaulotecnicoagricola@hotmail.com; ferragroestat@gmail.com; \\ eugeniodasilvaalexendre@gmail.com; kalinemeira@ hotmail.com, ${ }^{2}$ Universidade Federal de Campina Grande, \\ patriciaagroambiental@gmail.com; ${ }^{3}$ Faculdades Integradas de Patos, antonio.uepb@gmail.com.
}

\begin{abstract}
RESUMO: O aumento populacional mundial requer uma maior demanda por alimentos e, com isso, vem expansão de áreas agrícolas e/ou potencialização das áreas utilizadas atualmente através da agricultura convencional, que minam os recursos naturais. Entretanto, para solucionar essa problemática, faz-se necessário o uso de tecnologias e inovações que preservem os recursos naturais. Nesse contexto, objetivou-se avaliar a influência de concentrações de fitormônios na morfogênese e consumo de água por estacas de romã. O trabalho foi desenvolvido no Laboratório de Fitopatologia e em ambiente protegido, pertencentes ao CCAA/UEPB. Foram estudadas quatro concentrações de fitormônios $(0,25,50 \mathrm{e}$ $100 \%$ ) com três repetições. As variáveis analisadas foram: número de brotações, número de raízes e consumo de água pelas estacas de romãzeira. Os resultados demostraram que não houve efeito significativo das concentrações de fitormônios sobre as variáveis, embora, tenha-se observado variações no número de brotações e consumo de água. De acordo com as condições estudadas, concluiu-se que concentrações de fitormônios não influenciam a morfogênese e consumo de água por estacas de romã e outros estudos de maior complexidade envolvendo interações com outros fatores e concentrações dos fitormônios, bem como aumentar o intervalo de exposição das estacas de romãnzeira aos fitormônios, sejam realizados.
\end{abstract}

PALAVRAS-CHAVE: Punica granatum L; Agroecologia; Hormônios vegetais.

\section{INTRODUÇÃO}

O crescimento populacional no mundo requer o desenvolvimento de uma série de inovações tecnológicas para expansão agrícola e, assim, suprir a demanda por alimentos. Entretanto, grande parte dessas inovações tem sido desenvolvidas nos moldes da agricultura convencional, tais como: a biotecnologia e a nanotecnologia (SILVA, 2019a), engenharia genética e cultivos de transgênicos (REINHEIMER, 2018), agricultura industrial e da globalização, cultivos altamente mecanizados e com uso em demasia de insumos químicos (ALTIERI, 2010; SOARES et al., 2019).

Esse modelo de exploração agrícola, acarreta problemas ambientais seríssimos, sobretudo pela exaustão de recursos naturais, supressão da flora nativa para expansão de áreas agrícolas, acidificação dos solos e corpos hídricos, emissão de gases de efeito estufa, degradação da camada de ozônio e problemas que comprometem a resiliência dos agroecossistemas e causam perdas na biodiversidade (WANG et al., 2019).

Neste contexto, o aumento da produtividade para suprimento da demanda por alimentos, deve passar pelo crivo da agroecologia, ciência que visa a potencialização dos recursos naturais e não a depauperação dos recursos naturais, como na agricultura convencional. Assim, o investimento em tecnologias agroecológicas, como na produção de biomassa, que por sua vez, consiste em um mercado promissor, isso porque os recursos biológicos são produzidos e convertidos de forma sustentável em produtos de valor agregado (SÁNCHEZ et al., 2019), justificando o cultivo em ambiente protegido para obtenção de altas produtividades.

Diante do exposto, a produção de mudas em ambiente protegido com diferencial tecnológico, como por exemplo a aplicação de fitormônios exógenos para obtenção de melhor qualidade fisiológica das mudas pode ser uma estratégia para melhorar o desempenho das plantas no campo. Isso pode se refletir em maior produtividade no campo, pois os fitormônios podem proporcionar aumento no enraizamento das mudas e plantas, maior crescimento, maior floração e maior produção de frutos (SILVA, 2019b), assim proporcionando maior renda ao agricultor familiar.

Este cenário sugere que a produção de mudas de romã (Punica granatum L.) em ambiente protegido com aplicação de concentrações de fitormônios para indução de enraizamento e brotações, pode ser uma tecnologia viável para inserção na cadeia produtiva da cultura.

Nesta perspectiva, pesquisas para avaliação dos efeitos dos fatores citados anteriormente na romã são necessárias, pois os frutos da cultura são importantes e utilizados na indústria, por exemplo em panificação, bebidas e culinária, além de ser amplamente utilizada para o tratamento de várias doenças em diferentes culturas e civilizações (LOIZZO et al., 2019; SHAKHMATOV et al., 2019). Portanto, objetivou-se avaliar a influência de concentrações de fitormônios na morfogênese e consumo de água por estacas de romã. 
SILVA, J. P. et al. Morfogênese e consumo de água de estacas de romã sob aplicação de fitormônios exógenos. In: II Congresso Paraibano de Agroecologia \& IV Exposição Tecnológica, 2019. Anais... Caderno Verde de Agroecologia e Desenvolvimento Sustentável, Pombal, v. 9, n.7, e-6995, 2019.

\section{MATERIAL E MÉTODOS}

A pesquisa foi realizada entre os meses de agosto e novembro de 2018, no Laboratório de Fitopatologia e em ambiente protegido pertencentes ao Centro de Ciências Agrárias e Ambientais (CCAA) da Universidade Estadual da Paraíba (UEPB), localizado no município de Lagoa Seca - PB, nas coordenadas de Latitude $7^{\circ} 09^{\prime}$ S, Longitude $35^{\circ} 52^{\prime}$ W e altitude de $634 \mathrm{~m}$ (SOARES et al., 2017).

O delineamento experimental utilizado foi inteiramente casualizado, sendo 4 tratamentos, com três repetições. Os tratamentos consistiram de quatro concentrações de fitormônios exógenos (FEAT) obtidos de tubérculos de tiririca (Cyperus rotundus L.), (FEAT0 $=$ controle $0 \%$, EAT25 = 25\%, EAT50 = 50\% e EAT100 = 100\%).

Estacas semilenhosas, com $15 \mathrm{~cm}$ de comprimento e 4 a $5 \mathrm{~mm}$ de diâmetro, contendo de 2 a 3 nós, foram obtidas no período matutino, entre 7 e 9 horas, de duas plantas matrizes de romãzeira com seis anos de idade, cultivadas em residência particular, localizada na cidade de Campina Grande, PB, Brasil (7¹3'09.4"S 3551'55.9"W). As estacas foram inseridas em caixa de isopor, acomodadas em duas camadas de papel toalha umedecidas para evitar desidratação e transportadas para o Laboratório de Fitopatologia do CCAA/UEPB, onde foram lavadas em água corrente e desinfetadas com solução de hipoclorito de sódio a $2 \%$ por 5 minutos (PAIVA et al., 2015).

Para obtenção dos fitormônios, tubérculos de C. rotundus foram obtidos em uma área com infestação severa (SILVA FILHO et al., 2016). Os tubérculos frescos foram isolados, lavados com água e detergente neutro, secos em papel toalha e pesados. Foram utilizados $10 \mathrm{~g}$ de tubérculos, os quais foram triturados em liquidificador com $200 \mathrm{ml}$ de água destilada e peneirados para obtenção de uma solução estoque com 100\% do extrato (SIMÕES et al., 2003).

As concentrações correspondentes a cada tratamento foram obtidas por diluição da solução estoque em água destilada. Para o tratamento controle (FEAT0 $=0 \%$ ) foi utilizada água destilada, para FEAT25 = 25\% a diluição foi com $75 \%$ de água destilada $+25 \%$ de solução estoque, para FEAT50 $=50 \%$ a diluição foi com $50 \%$ água destilada + $50 \%$ de solução estoque, enquanto que para FEAT100 $=100 \%$ foi utilizada a solução estoque sem diluição (REZENDE et al., 2013; SCARIOT et al., 2017). Após isso, as bases das estacas $(10 \mathrm{~cm})$ foram imersas em soluções correspondentes a cada concentração de extrato aquoso de C. rotundus por 10 segundos, em recipientes de $0,5 \mathrm{~L}$ envoltos e cobertos com duas camadas de papel celofane de cor verde, notadamente por constituir-se em luz de segurança, sem influência sobre os fitocromos (PEREIRA et al., 2011). Posteriormente, as estacas foram plantadas em saco de polietileno de cor preta com capacidade volumétrica de $1 \mathrm{dm}^{3}$ preenchido com substrato constituído de solo arenoso e esterco bovino na proporção de 3:1 com umidade próxima da capacidade de campo. Os sacos contendo as estacas foram transferidos para o ambiente protegido correspondente a condição de luminosidade, que foi obtida numa mini-estufa com dimensão de 2,0 x 1,0 x 1,0 m de comprimento, largura e altura, respectivamente, onde foi coberta por uma camada de plástico transparente.

O manejo da irrigação foi realizado em turno de rega de quatro dias, utilizando-se do método de pesagens (PEREIRA et al., 2005), em que foi reposta a água evapotranspirada nos quatro dias que antecederam cada evento de irrigação.

Semanalmente, em cada unidade experimental, eram realizadas observações para quantificação do número de brotações (NBR). Transcorridos 60 dias após o plantio (DAP), as estacas foram removidas dos sacos de polietileno e separadas do substrato para avaliação do número de raízes (NRA).

Já o consumo de água evapotranspirada pelas estacas (CAE, em L) durante todo o experimento foi calculado a partir do somatório dos volumes de água requeridos (VAR, em L) para reposição do solo à condição de capacidade de campo em cada turno de rega, dado pela expressão "CAE $=\sum$ VAR".

Após a realização das avaliações, os dados foram tabulados, procedendo-se com o teste de normalidade de Shapiro-Wilk e análise de regressão polinomial e variância (F), através do software Sisvar 5.6 (FERREIRA, 2014).

\section{RESULTADOS E DISCUSSÃO}

Transcorridos 16 dias após o plantio (DAP) das estacas, foram verificadas 2, 4 e 2 brotações nas estacas com a aplicação de fitormônios nas concentrações de 0, 25 e 50\%, respectivamente (Figura 1). Ressalte-se que não foi realizada análise estatística dos dados de brotação em virtude da baixa taxa de brotação e consequente não normalidade dos dados.

Figura 1. Número de brotações de estacas de romã aos 16 DAP em ambiente protegido, sob aplicação de concentrações de fitormônios. Lagoa Seca, PB, Brasil, 2019.

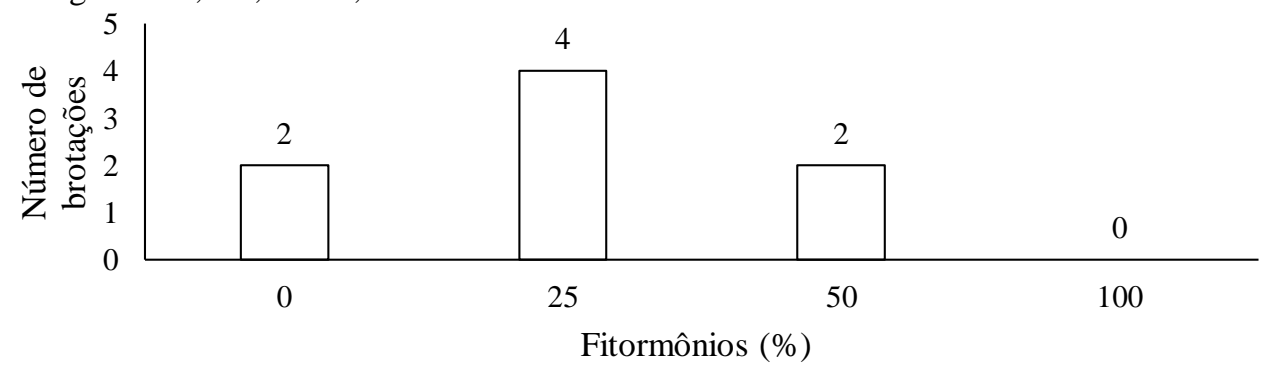


SILVA, J. P. et al. Morfogênese e consumo de água de estacas de romã sob aplicação de fitormônios exógenos. In: II Congresso Paraibano de Agroecologia \& IV Exposição Tecnológica, 2019. Anais... Caderno Verde de Agroecologia e Desenvolvimento Sustentável, Pombal, v. 9, n.7, e-6995, 2019.

Ao final do experimento, transcorridos $60 \mathrm{DAP}$, constatou-se que todas as brotações haviam morrido e que não houve formação de raízes em função das concentrações de fitormônios, inclusive o controle.

Algumas mudanças podem ter ocorridas na atmosfera luminosa das mini-estufas e podem ter ativado fotorreceptores específicos relacionados ao crescimento e desenvolvimento das brotações laterais das estacas de romã. De fato, fitocromos (phy) e criptocromos (cry) são relacionados à percepção do sinal luminoso e sinalização biossintética de fitormônios, como a giberelina (GA), refletindo em adaptações de crescimento em função da quantidade e qualidade da luz (TSUCHIDA-MAYAMA et al., 2010).

A ausência de formação de raízes e o fato das mudas não terem sobrevivido ao final do experimento estão relacionados aos efeitos da variação de desidratação e fitormônios no microclima do ambiente protegido (Cardoso et al., 2008; KATAYAMA et al., 2018) e atividade metabólica das estacas, sobretudo balanço de hormônios e mobilização destes para diferenciação celular e formação de brotações laterais e raízes (DUECK et al., 2016). De fato, Paiva et al. (2015) reportam que esses resultados indicam a sensibilidade da romãzeira a condições de clima quente e seco, fato principalmente observado na taxa de sobrevivência das mudas, possivelmente em função da desidratação das estacas devido à transpiração das folhas.

Com base nos dados obtidos, verificou-se que não houve efeito significativo $(P>0,05)$ das concentrações de fitormônios no consumo de água pelas estacas. Entretanto, foi verificado decréscimos de 76, 1,67 e $42 \mathrm{ml}$ no consumo de água pelas estacas de romãzeira, quando aplicadas as concentrações de fitormônios de 25; 50 e 100\%, respectivamente, em relação ao tratamento sem fitormônio (0\%), conforme figura 2.

Figura 2. Consumo de água evapotranspirada pelas estacas de romãzeira em função da aplicação de concentrações crescentes de fitormônios. Lagoa Seca, PB, Brasil, 2019.

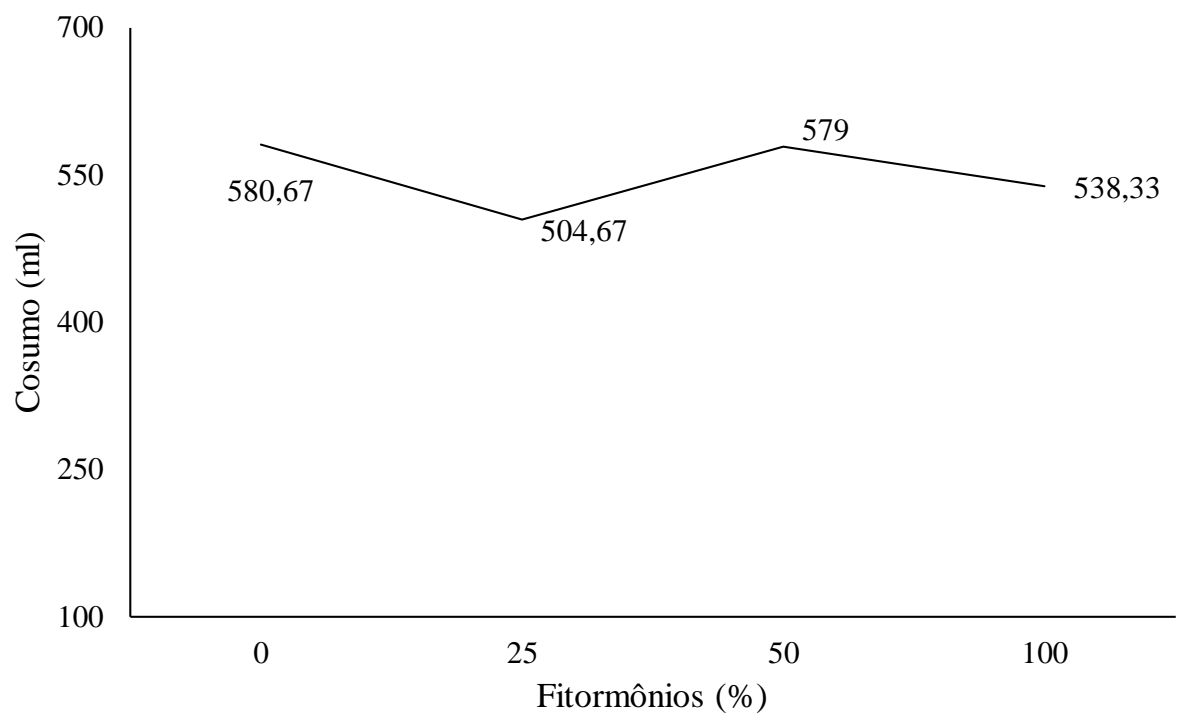

Por outro lado, um acréscimo de 74,3 e 33,6 $\mathrm{ml}$ no consumo de água pelas estacas de romãzeira para as concentrações de 50 e $100 \%$ de fitormônio, respectivamente, quando comparada a concentração de $25 \%$.

Diante disso, percebe-se que houve um grande esforço e gasto energético pelas estacas de romãzeira, para que as mesmas pudessem desenvolver suas raízes e brotos, o que foi em vão, pois não houve crescimento de raízes e brotações em todas as concentrações (Figura 1). Também se entende que o fitormônio na concentração de $25 \%$ pode ter retardado o desenvolvimento das estacas, onde na concentração de $50 \%$ já houve uma leve melhoria no consumo de água pelas raízes, entretanto, isso não foi convertido em maior número de brotações (Figura 1).

Em síntese, este estudo é importante para fornecer uma alternativa de produção de mudas e cultivo em ambiente protegido, sobretudo pelo fato das mudanças na disponibilidade e qualidade de luz no ambiente protegido promoverem mudança importantes na constituição bioquímica das plantas, como por exemplo acúmulo de pigmentos fotossintéticos e atividade de enzimas do metabolismo antioxidativo (MIAO et al., 2016).

Ressalta-se que, embora o cultivo em ambiente protegido seja considerado uma solução sustentável para a produção de alimentos em ambientes quentes e áridos, o clima severo e o déficit hídrico são obstáculos para o cultivo durante todo o ano, de modo que o projeto de estufa deve fornecer controle adequado de seu microclima, como temperatura, umidade relativa, concentração de $\mathrm{CO} 2$ e iluminação, sobretudo em função da cultura e das condições ambientais (GHANI et al., 2018). 
SILVA, J. P. et al. Morfogênese e consumo de água de estacas de romã sob aplicação de fitormônios exógenos. In: II Congresso Paraibano de Agroecologia \& IV Exposição Tecnológica, 2019. Anais... Caderno Verde de Agroecologia e Desenvolvimento Sustentável, Pombal, v. 9, n.7, e-6995, 2019.

\section{CONCLUSÕES}

De acordo com as condições estudadas, concluiu-se que concentrações de fitormônios não influenciam a morfogênese e consumo de água por estacas de romã e outros estudos de maior complexidade envolvendo interações com outros fatores e concentrações dos fitormônios, bem como aumentar o intervalo de exposição das estacas de romãnzeira aos fitormônios, sejam realizados.

\section{REFERÊNCIAS}

ALTIERI, M. A. Agroecologia, agricultura camponesa e soberania alimentar. Revista NERA, Presidente Prudente, ano 13, n.16, p.22-32, 2010.

DUECK, T.; TROUWBORST, G.; HOGEWONING, S.W.; MEINEN, E. Can a high red: Far red ratio replace temperature-induced inflorescence development in Phalaenopsis? Environ Experimental Botany, v.121, p.139-144, 2016.

FERREIRA, D.F. Sisvar: a Guide for its Bootstrap procedures in multiple comparisons. Ciência e Agrotecnoloiga, v.38, n.2, p.109-112, 2014.

GHANI, S.; BAKOCHRISTOU, F.; ELBIALY, E.M.A.A.; GAMALEDIN, S.M.A.; RASHWAN, M.M.; ABDELHALIM, A.M.; ISMAIL, S.M. Design challenges of agricultural greenhouses in hot and arid environments - A review. Engineering in Agriculture, Environment and Food. 2018. (In Press).

KATAYAMA, R.S.; GONÇALVES, G.K.; CALEFFI, H.V.; SARTURI, J.E.C.; VIEIRA, C.T.R.; MENDES, F.B.; POZZEBON, N.J. Eficiência de coberturas termorrefletoras e difusoras no desenvolvimento da alface submetida a diferentes doses de cama de aviário. Revista Científica Rural, v.20, n.2, p.1-16, 2018.

LOIZZO, M.R.; AIEllo, F.; TENUTA, M.C.; LEPORINI, M.; FAlCO, T.; TUNDIS, R. Pomegranate (Punica granatum L.). In: NABAVI, S.M.; SILVA A.S, editors. Nonvitamin and Nonmineral Nutritional Supplements. Academic Press; 2019.

MIAO, L.; ZHANG, Y.; YANG, X.; XIAO, J.; ZHANG, H.; ZHANG, Z.; WANG, Y.; JIANG, G. Colored light-quality selective plastic films affect anthocyanin content, enzyme activities, and the expression of flavonoid genes in strawberry (Fragaria $\times$ ananassa) fruit. Food Chemistry, v.207, p.93-100, 2016.

PAIVA, E.P.; ROCHA, R.H.C.; PRAXEDES, S.C.; GUEDES, W.A.; SÁ, F.V.S. Crescimento e qualidade de mudas de romãzeira 'wonderful' propagadas por estaquia. Revista Caatinga, Brasil, v.28, n.2, p.64-75, 2015.

PAIVA, E.P.; ROCHA, R.H.C.; PRAXEDES, S.C.; GUEDES, W.A.; SÁ, F.V.S. Crescimento e qualidade de mudas de romãzeira 'wonderful' propagadas por estaquia. Revista Caatinga, v.28, n.2, p.64-75, 2015.

PEREIRA, J.R.D.; CARVALHO, J.A.; MIGUEL, D.S.; SANTANA, M.J. Consumo de água pela cultura do crisântemo cultivada em ambiente protegido. Engenharia Agrícola, Brasil, v.25, n.3, p.651-659, 2005.

PEREIRA, M.C.; CARDOSO, N.P.; GIANCOTTI, P.R.F.; ALVES, P.L.A.C. Germinação de sementes de melão-desão-caetano sob variação de água, luz e temperatura. Bioscience Journal, n.279, n.3, p.363-370, 2011.

REINHEIMER, M. M. Cultivos de transgênicos e o discurso da sustentabilidade: um panorama sobre a Angola, Brasil, Cabo Verde, Moçambique e Protugal. REDE - Revista Eletrônica do PRODEMA, Fortaleza, Brasil, v. 12, n. 1, p.07$17,2018$.

REZENDE, F.P.F.; ZUFFELLATO-RIBAS, K.C.; KOEHLER, H.S. Aplicação de extratos de folhas e tubérbulos de Cyperus rotundus L. e de auxinas sintéticas na estaquia caulinar de Duranta repens L. Revista Brasileira de Plantas Medicinais, v.15, n.4, p.639-645, 2013.

SÁNCHEZ, J.; CURT, M. D.; ROBERT, N.; FERNÁNDEZ, J. Biomass Resources. In: LAGO C, CALDÉS N, LECHÓN Y, editors. The Role of Bioenergy in the Bioeconomy: Resources, Technologies, Sustainability and Policy. Academic Press; 2019. 
SILVA, J. P. et al. Morfogênese e consumo de água de estacas de romã sob aplicação de fitormônios exógenos. In: II Congresso Paraibano de Agroecologia \& IV Exposição Tecnológica, 2019. Anais... Caderno Verde de Agroecologia e Desenvolvimento Sustentável, Pombal, v. 9, n.7, e-6995, 2019.

SCARIOT, E.; BONOME, L.T.S.; BITTENCOURT, H.V.H.; LIMA, C.S.M. Extrato aquoso de Cyperus rotundus no enraizamento de estacas lenhosas de Prunus persica cv. 'Chimarrita'. Rev Revista de Ciências Agroveterinárias, v.16, n.2, p.195-200, 2017.

SHAKHMATOV, E.G.; MAKAROVA, E.M.; BELYY, V.A. Structural studies of biologically active pectin-containing polysaccharides of pomegranate Punica granatum. Int J Biol Macromolecules, n.122, p.29-36, 2019.

SILVA FILHO, A.M.; FERRAZ, R.L.S.; SILVA, E.S.; SILVA, G.N.; ANDRADE, L.O. Florística e potencial medicinal de plantas espontâneas em agroecossistema de pinhão bravo sob condição salina. Revista Brasileira de Agroecologia, v.11, n.1, p.45-53, 2016.

SILVA, D. Propagação in vitro e bioprospecção de extratos de plântulas de Libidibia ferrea (Fabaceae). Tese (Doutorado em Biotecnologia e Biodiversidade) - Instituto Nacional de Pesquisas da Amazônia, 125p, 2019 b.

SILVA, M. F. Estudos territoriais: impactos socioespaciais nas cidades do agronegócio brasileiro. BrazilianJournal of Development, Curitiba, v. 5, n. 7, p. 10079-10093, 2019a.

SIMÕES, C.M.O.; SCHENKEL, E.P.; GOSMANN, G.; MELLO, J.C.P.; MENTZ, L.A.; PETROVICK, P.R. Farmacognosia: da planta ao medicamento. 5th ed. Florianópolis: Ed. da UFSC; 2003. Portuguese.

SOARES, C .M.; ALVES, S. M. F. FREITAS, E. F. M.; ROCHA, I. J. F.; SANTOS, C. X.; FARIAS, H. F. L. Diagnosis of losses in the mechanized harvest of two cultivars of industrial tomato. Revista Brasileira de Ciências Agrárias, Recife, v.14, n.1, p.1-10, 2019.

SOARES, C.S.; SILVA, J.A.; SILVA, G.N. Produção de coentro em diferentes espaçamentos dos canais hidropônicos. Pesquisa Agropecuária Pernambucana, v.22, p.1-5, 2017.

TSUCHIDA-MAYAMA, T.; SAKAI, T.; HANADA, A.; UEHARA, Y.; ASAMI, T.; YAMAGUCHI, S. Role of the phytochrome and cryptochrome signaling pathways in hypocotyl phototropism. The Plant Journal, v.62, n.4, p.653$62,2010$.

WANG, F.; PENG, X.; WEI, R.; QIN, Y.; ZHU, X. Environmental behavior research in resources conservation and management: A case study of Resources, Conservation and Recycling. Resources, Conservation and Recycling, Michigan EUA, n.141, p.431-440, 2019.

\section{AGRADECIMENTOS}

Apoio financeiro: Fundação de Apoio à Pesquisa do Estado da Paraíba - FAPESQ. 